Original Article

\title{
EFFECT OF NONPHARMACOLOGICAL INTERVENTIONS ON DIETARY PRACTICES, ENERGY EXPENDITURE AND BIOCHEMICAL PARAMETERS OF HYPERCHOLESTEROLEMIC TYPE 2 DIABETIC SUBJECTS
}

\author{
Fadia Afnan', Farzana Saleh', Shirin Jahan Mumu², Afroza Akhter², Kazi Rumana Ahmed', \\ Sanzida Akter ${ }^{4}$ and Tanjuma Pervin ${ }^{5}$ \\ ${ }^{1}$ Department of Community Nutrition, Bangladesh Institute of Health Sciences (BIHS), Dhaka; ${ }^{2}$ Department of \\ Epidemiology \& Biostatistics, BIHS, Dhaka; ${ }^{3}$ Department of Health Education \& Health Promotion, BIHS, \\ Dhaka; ${ }^{4}$ Biomedical Research Group, Bangladesh Institute of Research and Rehabilitation for Diabetes, \\ Endocrine and Metabolic Disorders (BIRDEM), Dhaka; ${ }^{5}$ College of Home Economics, Dhaka
}

\begin{abstract}
Nonpharmacological interventions play an important role in the management of diabetes and its complications. This study analyzed the effect of nonpharmacological interventions on dietary practices, energy expenditure and management outcome in terms of glycemic and lipidemic status of type 2 diabetic subjects with hypercholesterolemia. These interventions included dietary advice, leaflets, televised lectures, booklets, posters and a bimonthly publication in Bangla. Eighty newly diagnosed type 2 diabetic subjects (male: female ratio 47:33, age $46 \pm 8$ years) with hypercholesterolemia (fasting serum total cholesterol $>200 \mathrm{mg} / \mathrm{dl}$ ) were selected from BIRDEM by purposive sampling. The first interview was taken before any intervention while the second interview was taken after a minimum interval of 8 weeks. The daily intake of macro- and micro- nutrients was assessed by 24$\mathrm{hr}$ recall method. Energy expenditure of the subjects was calculated by factorial method using physical activity level (WHO/FAO/UNU 1985). After intervention, the proportion of carbohydrate, protein and fat intake of the study subjects did not differ significantly compared to values before intervention. The daily intake of micronutrients also did not differ compared to those before intervention. No significant difference was found between pre and post intervention values of per day energy intake (kcal, $1621 \pm 426$ vs $1645 \pm 623$ ). Total energy expenditure after intervention was significantly higher $(1649 \pm 340)$ compared to before intervention $(1519 \pm 353, \mathrm{p}<0.002)$. After intervention, fasting serum glucose level $(7 \pm 1.43 \mathrm{mmol} / \mathrm{l})$, serum glucose $2 \mathrm{hrs}$ after breakfast $(11 \pm 4.1 \mathrm{mmol} / \mathrm{l})$ and total cholesterol $(217 \pm 35 \mathrm{mg} / \mathrm{dl})$ were significantly reduced compared to before intervention values $(9 \pm 4,16 \pm 7,231 \pm 32$ respectively; $\mathrm{p}=0.001$ for FSG, $\mathrm{p}=0.001$ for SGABF, $\mathrm{p}<0.001$ for total cholesterol). Nonpharmacological intervention was found to be effective in improving the management of diabetes and its complications.
\end{abstract}

Ibrahim Med. Coll. J. 2009; 3(2): 75-77

\section{Introduction}

The prevalence of diabetes and its complications are increasing worldwide at an alarming rate. According to the WHO estimates, approximately 171 million people of the world are suffering from diabetes and this number is supposed to more than double by the year 2030. ${ }^{1}$ Dyslipidemia is also a common problem

in type 2 diabetic population. Dyslipidemia is defined as total cholesterol $>200 \mathrm{mg} / \mathrm{dl}$, triglyceride $>150$ $\mathrm{mg} / \mathrm{dl}$, LDL-C $>100 \mathrm{mg} / \mathrm{dl}$, HDL-C $>50 \mathrm{mg} / \mathrm{dl}^{2}{ }^{2}$ Dietary restrictions, exercise and life style modifications are the initial nonpharmacological measures to control dyslipidemia. Balanced diet and

Address for Correspondence:

Farzana Saleh, Assistant Professor, Department of Community Nutrition, Bangladesh Institute of Health Sciences, Dhaka 1207, Bangladesh, e-mail: farzanasaleh_sumona@yahoo.com 
physical activity assists in controlling blood glucose and lipids.

The present study was conducted to determine the effect of nonpharmacological interventions on dietary practice, energy expenditure and management outcome in terms of glycemic and lipidemic status of type 2 diabetic subjects with hypercholesterolemia.

\section{Materials and Methods}

By purposive samply, eighty newly diagnosed type 2 diabetic subjects (male: female ratio 47:33, age $46 \pm 8$ years) with hypercholesterolemia (fasting serum total cholesterol $>200 \mathrm{mg} / \mathrm{dl}$ ) were recruited from the OutPatient Departments of BIRDEM.

The first interview was conducted before the intervention. Second interview was taken after a minimum interval of 8 weeks. The daily intake of macro and micronutrients was assessed by 24-hour recall method. Energy expenditure of the subjects was calculated by factorial method (WHO/FAO/UNU 1985). Data analysis was done by using SPSS PC version 10.0.

\section{Results}

A total of 80 newly diagnosed type 2 diabetic subjects with hypercholesterolemia were included in this study. The characteristics of the study subjects are shown in Table 1. Age (mean \pm SD) of the study subjects was $46 \pm 8.38$ years and among them 47 were males and 33 were females. Most of the subjects $(80 \%)$ came from the urban area. Only $28 \%$ subjects were graduates and $47 \%$ subjects did manual work. Weight, Body Mass Index (BMI), waist, hip, SBP and DBP of the study subjects were (mean \pm SD) $61.54 \pm 8.33,24.47 \pm$ $2.9,47 \pm 22,49 \pm 22,127.56 \pm 17.9$ and $81.06 \pm$ 7.23 respectively. According to BMI classification $35 \%$ were overweight.

Proportion of macro and micro intake of the study subjects did not differ significantly after getting intervention (Table 2). The daily energy intake and energy expenditure of the subjects is shown in Table 3. Energy expenditure significantly increased $(p<0.002)$ after getting intervention. After intervention, mean values of fasting serum glucose $(7 \pm 1.43 \mathrm{mmol} / \mathrm{l})$, serum glucose $2 \mathrm{hrs}$ after breakfast $(11 \pm 4.1 \mathrm{mmol} / \mathrm{l})$ and total cholesterol $(217 \pm 35 \mathrm{mg} / \mathrm{dl})$ were significantly reduced compared to before intervention values FSG $9 \pm 4 \mathrm{mmol} / \mathrm{l}, \mathrm{SGABF} 16 \pm 7 \mathrm{mmol} / \mathrm{l}, \mathrm{TC} 231 \pm 32$ $\mathrm{mg} / \mathrm{dl}$ respectively; $\mathrm{p}<0.001$ ) (Table 4 ).

\section{Discussion}

This study was designed to evaluate the effectiveness of nonpharmacological measures of newly diagnosed type 2 diabetic subjects with hypercholesterolemia. Diabetes and its complications can be prevented by lifestyle modifications like changes of dietary pattern, physical activity. Lifestyle modification is beneficial for preventing diabetes and CVD but is very difficult to sustain. In a Polish study, it was found that pharmacological as well as nonpharmacological interventions helped in normalization of glucose in patients with DM. ${ }^{3}$ In another study in Finland, after getting nonpharmacological intervention the overall incidence of diabetes was reduced by $58 \% .{ }^{4}$ In this

Table-1: Characteristics of the study subjects $(n=80)$

\begin{tabular}{l|c}
\hline Variables & \\
\hline Age (years) & $46 \pm 8.38$ \\
Sex & \\
$\quad$ Male & $47(59 \%)$ \\
$\quad$ Female & $33(41 \%)$ \\
Area & \\
$\quad$ Urban & $64(80 \%)$ \\
$\quad$ Rural & $12(15 \%)$ \\
Semi urban & $4(5 \%)$ \\
Level of Education & \\
Illiterate-primary & $31(39 \%)$ \\
$\quad$ SSC-HSC & $27(34 \%)$ \\
Graduate \& above & $22(28 \%)$ \\
Occupation & $38(47 \%)$ \\
$\quad$ Manual worker & $4(5 \%)$ \\
Labor & $38(48 \%)$ \\
Others & $61.54 \pm 8.33$ \\
Weight (Kg) & $24.47 \pm 2.9$ \\
BMI (Kg/m²) & $1(1 \%)$ \\
Under-nutrition $(<18.5)$ & $47(59 \%)$ \\
Normal weight $(18.5-25)$ & $28(35 \%)$ \\
Over-weight $(25-30)$ & $4(5 \%)$ \\
Obese $(>30)$ & $47 \pm 22$ \\
Waist (cm) & $49 \pm 22$ \\
Hip (cm) & $127.56 \pm 17.9$ \\
SBP (mm Hg) & $81.06 \pm 7.23$ \\
DBP (mm Hg) & \\
\hline & \\
\hline
\end{tabular}

Results are expressed as Number(\%), mean $\pm S D . S B P=$ Systolic blood pressure, DBP $=$ Diastolic blood pressure 
Table-2: Dietary intake of the study subjects after receiving intervention $(n=80)$

\begin{tabular}{l|c|c}
\hline \multirow{2}{*}{ Nutrients } & \multicolumn{2}{|c}{ Total Intake } \\
\cline { 2 - 3 } & Before & After \\
\hline Carbohydrate $(\mathrm{g} / \mathrm{d})$ & $239 \pm 65$ & $243 \pm 90$ \\
Protein $(\mathrm{g} / \mathrm{d})$ & $64 \pm 20$ & $71 \pm 46$ \\
Fat $(\mathrm{g} / \mathrm{d})$ & $45 \pm 13$ & $47 \pm 17$ \\
$\mathrm{Ca}(\mathrm{mg} / \mathrm{d})$ & $363 \pm 166$ & $280 \pm 111$ \\
Iron $(\mathrm{mg} / \mathrm{d})$ & $25 \pm 9$ & $24 \pm 7$ \\
Vitamin B1 (mg/d) & $1.2 \pm 0.45$ & $1.17 \pm 0.42$ \\
Vitamin B2 (mg/d) & $0.87 \pm 0.36$ & $0.76(0.32-2.46)$ \\
Vitamin C (mg/d) & $40 \pm 18$ & $35(7.5-179)$ \\
Retinol $(\mu \mathrm{g} / \mathrm{d})$ & $545 \pm 243$ & $597(212-7880)$ \\
\hline
\end{tabular}

Results are expressed as mean $\pm S D$ and median (Range).

Table-3: Energy intake and energy expenditure of the study subjects after receiving intervention $(n=80)$

\begin{tabular}{lcc|c}
\hline Variables & Before & After & t/p \\
\hline Energy intake (Kcal/ day) & $1621 \pm 426$ & $1645 \pm 623$ & $0.28 / 0.77$ \\
Energy expenditure & $1519 \pm 353$ & $1649 \pm 340$ & $3.25 / 0.002^{*}$ \\
\hline
\end{tabular}

Results are expressed as mean $\pm S D$. Paired t- test was performed as the test of significance, $p<0.05$ was taken as level of significance.

Table-4: Glycemic status and lipid profile of the study subjects after receiving intervention $(n=80)$

\begin{tabular}{lcc|c}
\hline Variables & Before & After & t/p \\
\hline FSG $(\mathrm{mmol} / \mathrm{dl})$ & $9 \pm 3.89$ & $7 \pm 1.43$ & $4.2 / 0.001^{*}$ \\
SGABF $(\mathrm{mmol} / \mathrm{dl})$ & $16 \pm 6.46$ & $11 \pm 4.08$ & $6.4 / 0.001^{*}$ \\
Total Cholesterol $(\mathrm{mg} / \mathrm{dl})$ & $231 \pm 31.89$ & $217 \pm 35.10$ & $7.5 / 0.001^{*}$ \\
\hline
\end{tabular}

Results expressed as mean $\pm S D, F S G=$ Fasting Serum Glucose, $S G A B F=$ Serum Glucose After Break fast, $T C=$ Total Cholesterol. Paired t-test was performed as the test of significance, $p<0.05$ was taken as level of significance.

study, dietary intake of macro and micro nutrients of the study subjects did not significantly differ before and after intervention. After receiving nonpharmacological intervention, energy expenditure of the study subjects significantly increased $(\mathrm{p}<0.002)$. Majority (60\%) of the participants performed exercise according to the instruction of the physician. It was seen that changes in dietary practice was relatively more difficult to change compared to initiation of physical exercise. Nonpharmacological interventions that emphasize lifestyle changes, including education, regular physical activity and behavior modification are important components in maintenance of the desired weight. After getting intervention, glycemic and total cholesterol level of the study subjects were significantly reduced $(\mathrm{p}<0.001)$. In Sweden ${ }^{5}$ and China ${ }^{6}$ studies also provided that changes in lifestyle were effective in preventing diabetes and its complications. Results of this study suggest that nonpharmacological interventions are effective in the metabolic control of hypercholesterolemic diabetic subjects. It may also suggest that more focused motivation is needed to improve the dietary practices of this population to prevent diabetes related complications.

\section{Acknowledgment}

The study was supported by ENRECA under DANIDA, Denmark; International Program in the Chemical Sciences (IPICS), Uppasala University, Sweden; Bangladesh Diabetic Somity.

\section{References}

1. Wild S, Roglic G, Green A, Sicree R, King H. Global prevalence of diabetes. Diabetes Care 2004; 27: 1047 1052.

2. American diabetes Association: Standards of medical care in diabetes-2007. Diabetes Care 2007; 30(Suppl 1): S16.

3. Strus A, Szepietowska B, Zonenberg A, Nikolajuk A, GÓrska M, Szelachowska M. The possibility of prevention of type 2 diabetes. Endokrynol Pol 2008; 59: 6-12.

4. Tuomilehto J, LindstrÖm J, Eriksson GJ, Valle TT, Hämäläine $\mathrm{H}$, Parikka I P, et al. Prevention of type 2 diabetes mellitus by changes in lifestyle among subjects with impaired glucose tolerance. N Engl J Med 2001; 344(18): 1343-1349.

5. Eriksson KF, Lindgarde F. Prevention of type 2 (noninsulin-dependent) diabetes mellitus by diet and physical exercise: the 6-year Malmo feasibility study. Diabetologia 1991; 34:891-8.

6. Pan XR, Li GW, Hu YH, et al. Effects of diet and exercise in preventing NIDDM in people with impaired glucose tolerance: the Da Qing IGT and Diabetes Study. Diabetes Care 1997; 20: 537-44. 